\title{
Expression of CD9 and CD82 in papillary thyroid microcarcinoma and its prognostic significance
}

\author{
Taeyeong Kim ${ }^{1}$, Yonhee Kim $^{2}$, Hyeong Ju Kwon ${ }^{1}$ \\ ${ }^{1}$ Department of Pathology, Yonsei University Wonju College of Medicine, Wonju, Republic of Korea \\ ${ }^{2}$ Soon Chun Hyang University Hospital Seoul, Republic of Korea
}

\begin{abstract}
Introduction: papillary thyroid microcarcinoma is a well-known malignant neoplasm with good prognosis. The known prognostic factors are patient's age, multifocality, and extrathyroidal extension. CD9 and CD82, members of the tetraspanin family, are expressed in numerous cancer cells and play many roles associated with the cellular process.

Material and methods: we investigated the immunohistochemical expression of CD9 and CD82 in papillary thyroid microcarcinoma and analysed the clinicopathological and prognostic significance. For the retrospective analysis, we collected the cases of 553 PTMC patients who had undergone thyroidectomy.

Results: The group with lymph node metastasis showed higher immunostaining intensity for CD9 than the group without metastasis $(p=0.002)$. In multivariate analysis, high CD9 intensity $(O R=1.58$ in $3+, p=0.0025)$ correlated with lymph node metastasis.

Conclusion: We suggest CD9 as a predictive prognostic factor for lymph node metastasis in PTMC. (Endokrynol Pol 2019; 70 (3): 224-231)

Key words: CD9; CD82; prognosis; papillary thyroid microcarcinoma
\end{abstract}

\section{Introduction}

Papillary thyroid microcarcinoma (PTMC) is a well-known malignant neoplasm with good prognosis [1]. PTMC is defined as a papillary thyroid carcinoma with a tumour size less than $10 \mathrm{~mm}$. Development of fine-needle aspiration biopsy (FNAB) led to increased detection of newly diagnosed PTMC cases [2]. Because of the favourable prognosis and indolent biological behaviour, management of PTMC has been controversial. Clinicians have a variety of options, from active surveillance to total thyroidectomy with lymph node dissection. Whichever treatment method is chosen, it is important to predict the prognosis of cancer patients for additional therapy or follow-up. In PTMC, the known prognostic factors associated with lymph node metastasis or tumour recurrence are patient's age, multifocality, and extrathyroidal extension [3].

Several molecular prognostic factors of PTMC have been reported. BRAF mutation, which is commonly detected in papillary thyroid carcinoma, is associated with poor prognosis [4]. Another study reported that the absence of EGFR expression and COX-2 expression was associated with poor prognosis in patients with PTMC [5]. In addition, molecular studies of papillary carcinoma have been well studied, but rarely in microcarcinoma.

CD9 and CD82, members of the tetraspanin family, are expressed in numerous cancer cells and mediate multiple cellular processes. Decreased CD9 expression has been reported to be related with the progression of breast, stomach, colon, prostate, and non-small cell lung cancer [6]. CD82 expression also has been reported to be related with the progression, metastasis, or poor prognosis of prostate, breast, larynx, gastrointestinal, and thyroid cancer [7-10]. However, the role of these molecules in PTMC is not well-known.

In our previous study, CD82 expression is associated with poor prognosis of clear cell renal cell carcinoma (CCRCC) [11]. CCRCC shares some of the molecular changes with PTMC. The tumour suppressor gene, thyroid hormone receptor beta (THRB), is downregulated in other tumours including papillary thyroid carcinoma and has been reported to be downregulated in CCRCC $[12,13]$. Therefore, some molecules may predict prognosis in both PTMC and CCRCC.

This study was designed to evaluate the immunohistochemical expression of CD9 and CD82 in PTMC and to determine the clinicopathological and prognostic significance. 


\section{Material and methods}

\section{Patients and tissue specimens}

For the retrospective analysis, we collected the cases of 553 PTMC patients who had undergone thyroidectomy from January to December 2010 at the Severance Hospital (Seoul, South Korea). Samples were obtained from 107 men and 446 women, with a mean age of 44.57 years. The mean tumour size was $0.53 \mathrm{~cm}$. The clinicopathological information was collected from electronic medical records, pathological reports, and review of slides. The histologic subtype, tumour stage, and lymph node metastasis were determined by pathological review. The BRAF mutation was determined by polymerase chain reaction based on aspiration cytology or formalin-fixed, paraffin-embedded samples.

\section{Tissue microarray and immunohistochemistry}

The H\&E slides of all cases were reviewed, and one representative core tissue $(2 \mathrm{~mm}$ in diameter) was obtained from each paraffin block and placed in a new paraffin block using a trephine apparatus (Superbiochips Laboratories, Seoul, Korea). Immunohistochemical staining was performed using the Bond-Max Autostainer (Leica Microsystems, IL, USA). After heat-induced antigen retrieval, mouse monoclonal anti-human CD9 antibody (NovoCastra, Newcastle Upon Tyne, UK, dilution 1:250) and mouse monoclonal anti-human CD82 antibody (NovoCastra, dilution 1:50) were incubated with the samples for $15 \mathrm{~min}$. The binding of the primary antibody was detected using the Bond Polymer Refine Detection kit (Leica Microsystems) according to the manufacturer's instructions. The CD9 and CD82 immunoreactivity was scored using the $\mathrm{H}$-score method, which classifies the percentages of cells stained with intensities of $0,1+, 2+$, and $3+$ as follows: $H$-score $=\Sigma$ [ntensity $(0,1,2,3) \times$ the extent of each staining intensity (\%)] (Fig. 1). The $\mathrm{H}$-score ranges from 0 to 300 . The results were evaluated independently by two pathologists who were blinded to the outcome and scores of the other observer.

\section{Statistical analysis}

Statistical analyses were performed using SPSS software (version 23.0; SPSS Inc., Chicago, IL, USA). The correlations between CD9 and CD82 expression and clinicopathological characteristics were analysed by Pearson's $\chi^{2}$ test. The H-score of CD9 and CD82 was also analysed by Pearson's $\chi^{2}$ test. The parameters that were significant in the univariate analysis $(p<0.05)$ were analysed using a multivariate Cox regression model to evaluate the incremental statistical power and independence of prognostic impact. All of the statistical tests were two sided, and $\mathrm{p}$ values less than 0.05 were considered statistically significant.

\section{Results}

\section{CD9 and CD82 expression in PTMC}

CD9 was present in the cytoplasm and/or membrane, and of the 544 PTMC samples, $433(80.6 \%)$ were positive and $111(20.4 \%)$ were negative for CD9 immunohistochemical stain. CD82 was also observed in the cytoplasm and/or membrane. $375(68.68 \%)$ were positive and 171 (31.32\%) were negative for CD82 immunohistochemical stain (Tab. II).

\section{Association between CD9, CD82 expression, and clinicopathologic parameters}

There was a statistically significant correlation between high CD9 immunostaining intensity and males comparing to females ( $p=0.0089$ and Pearson's $r=0.001)$. In addition, the group with lymph node metastasis showed higher immunostaining intensity for CD9 than the group without metastasis $(\mathrm{p}=0.002)$. The intensity of CD9 was found to be associated with $\mathrm{N}$-stage. This was statistically significant $(p=0.0535)$. The higher CD82 immunostaining intensity was found to be associated with age $(\leq 45)(p=0.0226)$ and the absence of lymphocytic thyroiditis $(p=0.0111)$. Other parameters
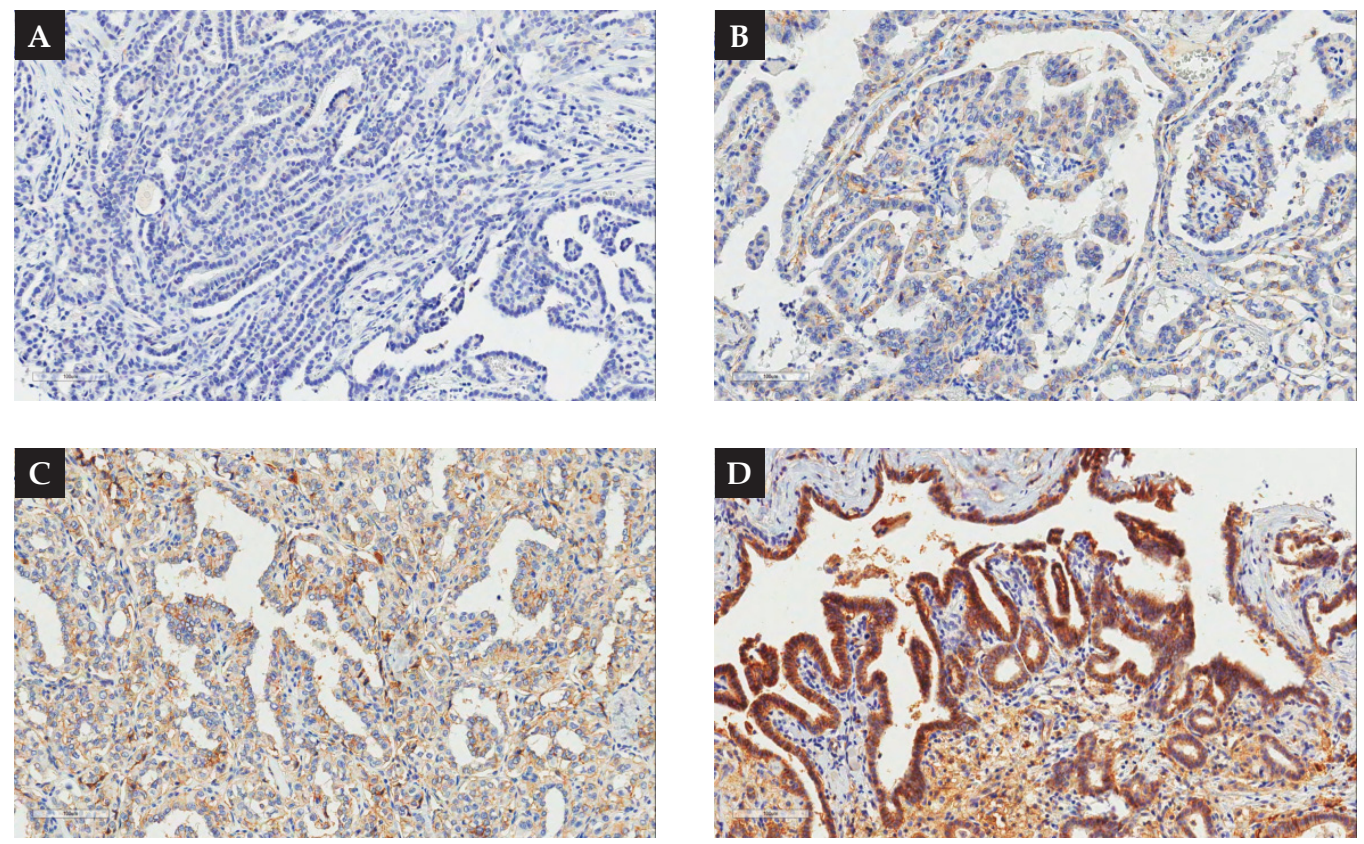

Figure 1. Each immunostained slide was classified into $0,1+, 2+$, or $3+$ depending on the intensity of the staining. A. No expression (0); B. Weak intensity (1+); C. Moderate intensity (2+); D. Strong intensity (3+) 
Table I. Clinicopathological characteristics of the patients with papillary thyroid microcarcinoma (PTMC)

\begin{tabular}{|c|c|c|}
\hline Characteristic & & Total $(n=553)$ \\
\hline \multirow[t]{2}{*}{ Age (years) } & $\leq 45$ & $297(53.71 \%)$ \\
\hline & $>45$ & $256(46.29 \%)$ \\
\hline \multirow[t]{2}{*}{ Size $[\mathrm{cm}]$} & $\leq 0.5$ & $325(58.77 \%)$ \\
\hline & $>0.5$ & 228 (41.23\%) \\
\hline \multirow[t]{2}{*}{ Gender } & Male & $107(19.35 \%)$ \\
\hline & Female & 446 (80.65\%) \\
\hline \multirow[t]{2}{*}{ Location } & Left & 271 (49.01\%) \\
\hline & Right & $282(50.99 \%)$ \\
\hline \multirow[t]{2}{*}{ Tumour extent } & Intrathyroidal & $336(60.76 \%)$ \\
\hline & Extrathyroidal & $217(39.24 \%)$ \\
\hline \multirow[t]{2}{*}{ LN metastasis } & Absent & $368(72.44 \%)$ \\
\hline & Present & $140(27.56 \%)$ \\
\hline \multirow[t]{4}{*}{$\mathrm{N}$-stage } & NO & 367 (66.37\%) \\
\hline & N1a & $127(22.97 \%)$ \\
\hline & $\mathrm{N} 1 \mathrm{~b}$ & $14(2.53 \%)$ \\
\hline & $\mathrm{Nx}$ & $45(8.14 \%)$ \\
\hline \multirow[t]{3}{*}{$B R A F$ mutation } & Negative & $17(3.07 \%)$ \\
\hline & Positive & $37(6.69 \%)$ \\
\hline & Not performed & $499(90.24 \%)$ \\
\hline \multirow[t]{2}{*}{ Adenomatous hyperplasia } & Absent & $440(79.57 \%)$ \\
\hline & Present & $113(20.43 \%)$ \\
\hline \multirow[t]{2}{*}{ Lymphocytic thyroiditis } & Absent & 387 (69.98\%) \\
\hline & Present & $166(30.02 \%)$ \\
\hline
\end{tabular}

did not show a significant correlation with the intensity of staining for CD9 and CD82 (Tab. III).

\section{Association between H-score of CD9, CD82 expression, and clinicopathological parameters}

The CD9 H-score was significantly higher in the group with a size of less than $0.5 \mathrm{~cm}(p=0.0240)$. Male gender $(\mathrm{p}=0.0052)$ and presence of adenomatous hyperplasia $(p=0.0272)$ also showed significantly high CD9 H-score. The CD82 H-score did not show significant association with any clinicopathological parameters (Tab. IV).

\section{Univariate and multivariate logistic regression for lymph node metastasis}

In univariate analysis, age $(\leq 45)(\mathrm{OR}=1.72, \mathrm{p}=0.0079)$, size $(>0.5 \mathrm{~cm})(\mathrm{OR}=2.2, \mathrm{p}<0.0001)$, male gender $(\mathrm{OR}=2.6, \mathrm{p}<0.0001)$, absence of lymphocytic thyroiditis $(\mathrm{OR}=1.68, \mathrm{p}=0.021)$, and high CD9 intensity $(\mathrm{OR}=1.95$ in $3+, \mathrm{p}=0.0025)$ were correlated with lymph node metastasis. In multivariate analysis, age $(\leq 45)(\mathrm{OR}=1.77, \mathrm{p}=0.0087)$, size $(>0.5 \mathrm{~cm})(\mathrm{OR}=2.29$, $\mathrm{p}=0.0001)$, male gender $(\mathrm{OR}=2.36, \mathrm{p}=0.0008)$, and
Table II. CD9 and CD82 expression in papillary thyroid microcarcinoma (PTMC)

\begin{tabular}{|c|c|c|c|}
\hline & & & Total $(n=533)$ \\
\hline \multirow{7}{*}{ CD9 } & \multirow{2}{*}{ Expression (\%) } & 0 & $111(20.4 \%)$ \\
\hline & & $>0$ & $433(80.6 \%)$ \\
\hline & \multirow{4}{*}{ Intensity } & 0 & $111(20.4 \%)$ \\
\hline & & 1 & $200(36.76 \%)$ \\
\hline & & 2 & 191 (35.76\%) \\
\hline & & 3 & $42(7.72 \%)$ \\
\hline & H-score (mean \pm SD) & \multicolumn{2}{|c|}{$100.09 \pm 87.10$} \\
\hline \multirow{7}{*}{ CD82 } & \multirow{2}{*}{ Expression (\%) } & 0 & $171(31.32 \%)$ \\
\hline & & $>0$ & $375(68.68 \%)$ \\
\hline & \multirow{4}{*}{ Intensity } & 0 & 171 (31.32\%) \\
\hline & & 1 & $213(39.01 \%)$ \\
\hline & & 2 & $124(22.71 \%)$ \\
\hline & & 3 & $37(6.78 \%)$ \\
\hline & H-score (mean \pm SD) & \multicolumn{2}{|c|}{$93.42 \pm 90.71$} \\
\hline
\end{tabular}

high CD9 intensity (OR $=1.58$ in $3+, p=0.0061)$ were correlated with lymph node metastasis (Tab. V).

\section{Discussion}

Tetraspanin family molecules are involved in a variety of physiological and pathological processes including signal transduction, cell adhesion, proliferation, differentiation, and migration [14, 15]. Among the tetraspanin family molecules, CD9 is one of the most studied molecules in human cancer, and there are many reports on its association with prognosis. A recent study reported that high expression of CD9 in colorectal cancer cells is associated with favourable disease-free survival [16]. In addition, follicular lymphoma, breast cancer, ovarian cancer, stomach, and malignant melanoma have been reported to show an inverse correlation between CD9 expression and patient survival rate [17-21]. In this study, the association between CD9 expression and survival rate was not analysed, because most patients with PTMC are alive and the analysis may be insignificant.

CD9 is also known as motility-related protein-1 (MRP-1); one of the functions of CD9 in cancer cells is to contribute to cell motility and migration. Some studies suggested that CD9 is associated with EW1 family, epidermal growth factor receptor (EGFR), and discoidin domain receptor 1 (DDR1), regulating cell motility. The association with EGFR induces the EGF-dependent chemotactic migration to extracellular matrix, and tumour cells gain the ability of extra- or intravasation [22-25]. Angiogenic activity of CD9 by interacting with vascular endothelial growth factor (VEGF) receptor 3 and integrin has also been suggested [26, 27]. Our results showed 


\section{|| 4 |}

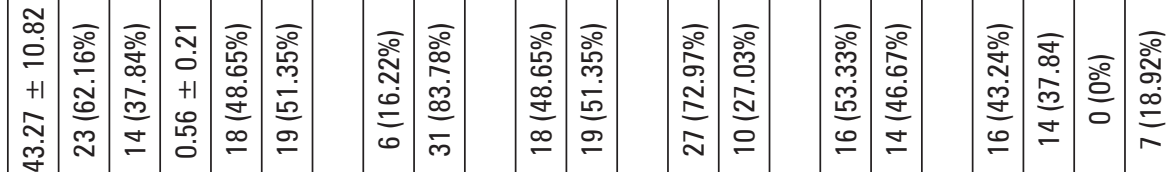

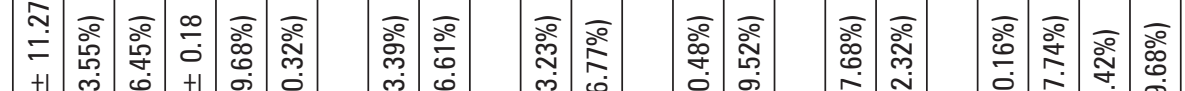

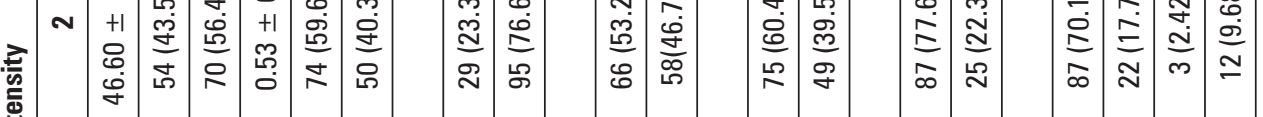

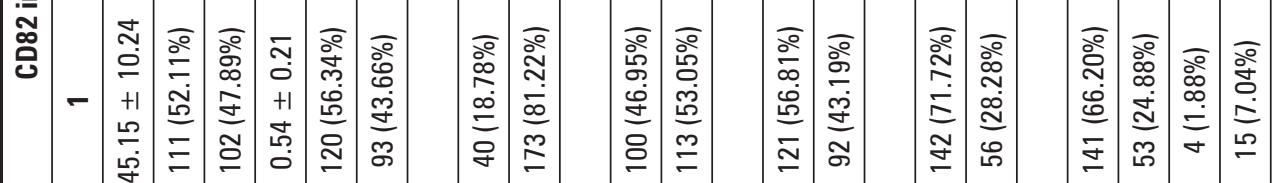

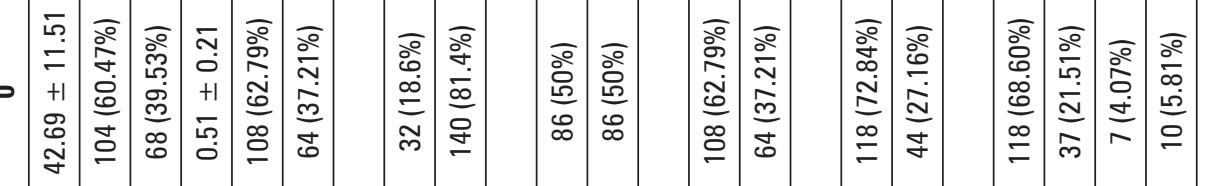

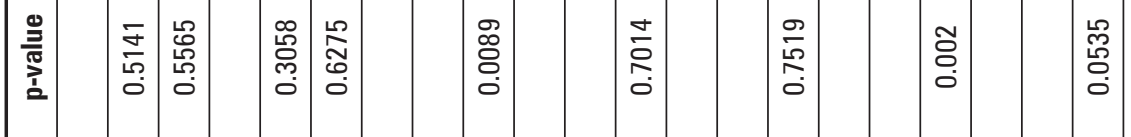

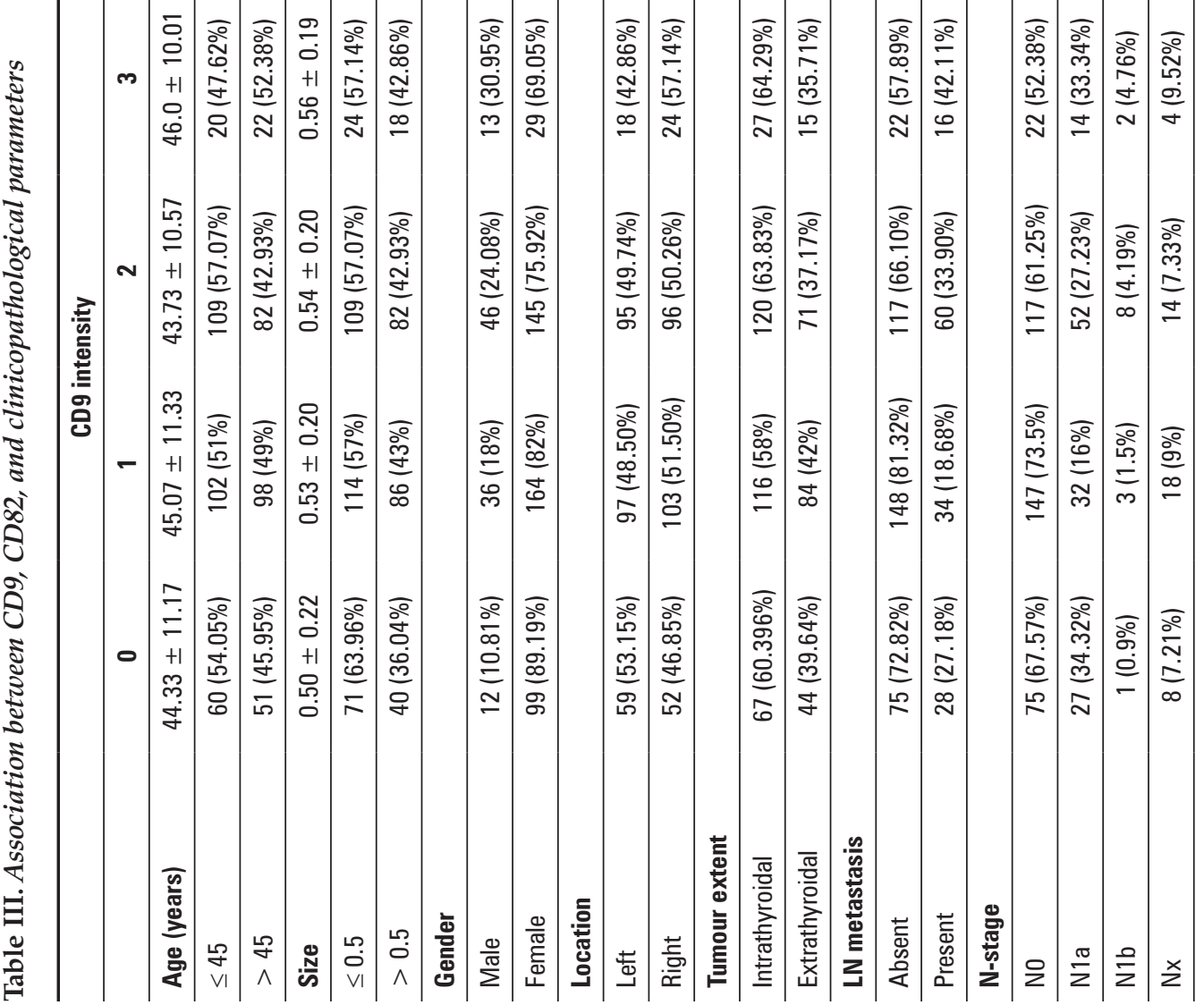




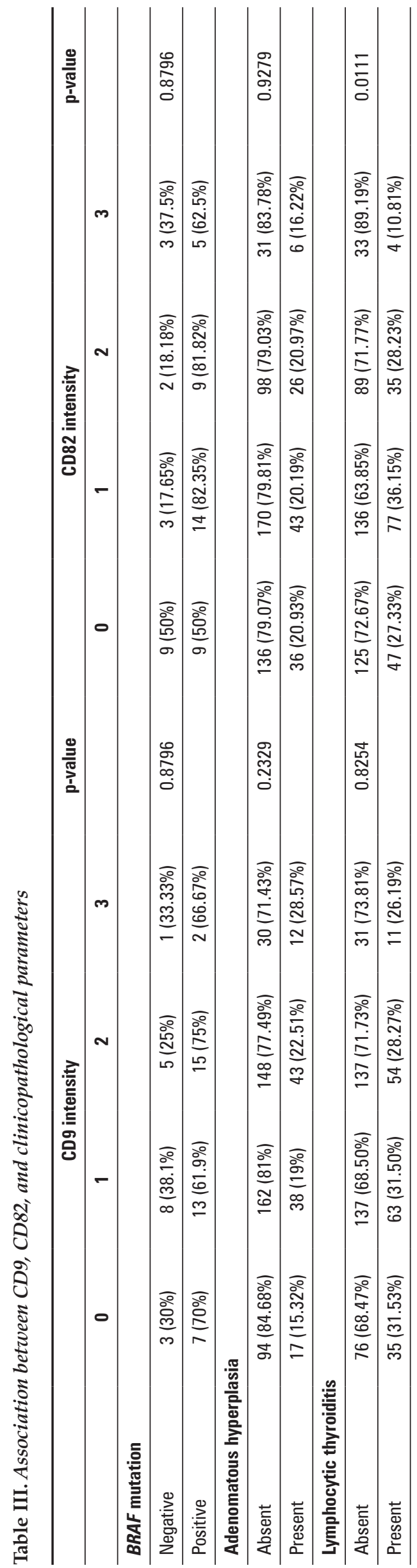

that CD9 staining intensity was positively correlated with lymph node metastasis. This result appears to be due to the mechanisms described above.

Paradoxically, several reports suggested that CD9 inhibits metastasis. In cancer cell line studies, a suggested mechanism is inhibition of integrin-mediated motility of various cancer cells including lung, breast, stomach, skin, pancreas, and urinary bladder [28]. Other studies suggested that CD9 may downregulate Wiskott-Aldrich syndrome protein 2 (WAVE 2), and downregulated WAVE 2 results in suppression of tumour cell motility by affecting the actin cytoskeleton $[29,30]$.

There are also some studies about other mechanisms that CD9 is involved in in various cancer cells. One study reported that downregulation of CD9 in pancreatic cancer cells induces upregulation of the epidermal growth factor, thereby promoting cancer cell growth and metastasis [31]. In ovarian cancer, upregulation of $\mathrm{CD} 9$ is related to the induction of TNF- $\alpha$ gene expression and constitutive NF- $\kappa$ B activation [32]. In a review article, the function of CD9 is summarised as follows: i) interaction with endothelial cells and induction of transendothelial migration of the tumour cells; ii) enhancement of the motility of tumour cells; iii) promotion of tumour cell growth and prevention of apoptosis; and iv) an important marker for the identification of cancer stem cells [33]. These various mechanisms suggest that $\mathrm{CD} 9$ may affect prognosis in a variety of ways.

CD82 (KAI1) also belongs to the tetraspanin family, and there have been studies about functions in cancer cells. Recent studies have suggested that CD82 expression suppresses environmental angiogenesis by inhibition of production of interleukin 6 (IL-6) and vascular endothelial growth factor (VEGF) in malignant melanoma [34]. In the papillary thyroid carcinoma, down-regulation of CD82 is significantly related to lymph node metastasis and anaplastic transformation [35]. Another study reported that CD82 expression was correlated with pathological TNM status of thyroid cancer, and they suggested that down-regulation of CD82 expression in thyroid cancer cells may reflect an increased metastatic potential [10]. In this study, however, CD82 expression is correlated with patient age and lymphocytic thyroiditis, not with lymph node metastasis. Contrary to the above studies, normal angiogenesis without obvious vascular defect was shown in CD82-null mice [36]. The role of CD82 in cancer cells remains unclear.

$\mathrm{H}$-score of CD9 is associated with adenomatous hyperplasia alone, and that of CD82 is not correlated with any clinicopathological parameters. Because the $\mathrm{H}-$ score is the value obtained by multiplying the staining intensity by the extent, the staining extent seems not to 
Table IV. Univariate and multivariate logistic regression for lymph node metastasis

\begin{tabular}{|c|c|c|c|c|}
\hline & \multicolumn{2}{|c|}{ CD9 } & \multicolumn{2}{|c|}{ CD82 } \\
\hline & H-score & p-value & H-score & p-value \\
\hline Age (years) & 0.0006 & 0.8822 & 0.074 & 0.086 \\
\hline$\leq 45$ & $101.1 \pm 86.60$ & 0.7650 & $88.29 \pm 92.40$ & 0.1568 \\
\hline$>45$ & $98.89 \pm 87.82$ & & $99.31 \pm 88.53$ & \\
\hline Size & 0.097 & 0.0240 & 0.057 & 0.1857 \\
\hline$\leq 0.5$ & $97.33 \pm 87.15$ & 0.3803 & $89.47 \pm 90.43$ & 0.2266 \\
\hline$>0.5$ & $104.0 \pm 87.06$ & & $99.0 \pm 91.0$ & \\
\hline \multicolumn{5}{|l|}{ Gender } \\
\hline Male & $121.1 \pm 89.19$ & 0.0052 & $98.97 \pm 90.87$ & 0.4803 \\
\hline Female & $94.94 \pm 85.90$ & & $92.06 \pm 90.72$ & \\
\hline \multicolumn{5}{|l|}{ Location } \\
\hline Left & $99.37 \pm 87.07$ & 0.8482 & $91.83 \pm 89.07$ & 0.6799 \\
\hline Right & $100.8 \pm 87.27$ & & $95.04 \pm 92.48$ & \\
\hline \multicolumn{5}{|c|}{ Tumour extent } \\
\hline Intrathyroidal & $102.3 \pm 88.42$ & 0.4596 & $96.51 \pm 95.30$ & 0.3091 \\
\hline Extrathyroidal & $96.66 \pm 85.10$ & & $88.65 \pm 83.13$ & \\
\hline \multicolumn{5}{|l|}{ LN metastasis } \\
\hline Absent & $96.26 \pm 83.42$ & 0.2043 & $89.67 \pm 86.72$ & 0.0533 \\
\hline Present & $11.4 \pm 94.90$ & & $93.81 \pm 95.78$ & \\
\hline \multicolumn{5}{|l|}{ N-stage } \\
\hline NO & $96.25 \pm 83.42$ & 0.2043 & $89.67 \pm 86.72$ & 0.0533 \\
\hline N1a & $108.32 \pm 95.89$ & & $97.82 \pm 97.25$ & \\
\hline N1b & $138.21 \pm 79.65$ & & $58.21 \pm 70.15$ & \\
\hline $\mathrm{Nx}$ & $96.14 \pm 91.05$ & & $122.84 \pm 103.41$ & \\
\hline \multicolumn{5}{|c|}{ BRAF mutation } \\
\hline Negative & $93.53 \pm 93.45$ & 0.6509 & $92.94 \pm 119.8$ & 0.4627 \\
\hline Positive & $105.1 \pm 84.01$ & & $116.2 \pm 101.3$ & \\
\hline \multicolumn{5}{|c|}{ Adenomatous hyperplasia } \\
\hline Absent & $95.94 \pm 85.47$ & 0.0272 & $94.53 \pm 91.26$ & 0.5708 \\
\hline Present & $116.5 \pm 91.80$ & & $89.05 \pm 88.79$ & \\
\hline \multicolumn{5}{|c|}{ Lymphocytic thyroiditis } \\
\hline Absent & $101.9 \pm 87.86$ & 0.4589 & $97.44 \pm 94.98$ & 0.0878 \\
\hline Present & $95.86 \pm 85.39$ & & $83.96 \pm 79.24$ & \\
\hline
\end{tabular}

be important in affecting clinicopathological parameters in both CD9 and CD82 immunostaining.

This study represents an analysis of the association between two tetraspanin family molecules and clinicopathologic parameters of PTMC, especially lymph node metastasis. Although CD9 staining intensity is significantly associated with lymph node metastasis, it is difficult to predict the complicated mechanism of lymph node metastasis based only on CD9 and CD82. Additional risk factors may affect CD9 expression and lymph node metastasis. The detailed mechanism should be elucidated through additional studies using various molecules and cancer cell lines.

\section{Conclusion}

In conclusion, although PTMC has a favourable prognosis, predicting the prognostic factors is very important for patient management. We suggest CD9 as a predictive prognostic factor for lymph node metastasis in PTMC. Further studies with other cancers are needed to delineate the function of CD9. 
Table V. Univariate and multivariate logistic regression for lymph node metastasis

\begin{tabular}{|c|c|c|c|c|c|c|}
\hline & \multicolumn{3}{|c|}{ Univariate analysis } & \multicolumn{3}{|c|}{ Multivariate analysis } \\
\hline & OR & $95 \% \mathrm{CI}$ & p-value & OR & $95 \% \mathrm{Cl}$ & p-value \\
\hline \multicolumn{7}{|l|}{ Age (years) } \\
\hline$\leq 45$ & 1.72 & $(1.15 \sim 2.58)$ & 0.0079 & 1.77 & $(1.16 \sim 2.72)$ & 0.0087 \\
\hline$>45$ & 1 & & & 1 & & \\
\hline \multicolumn{7}{|l|}{ Size } \\
\hline$\leq 0.5$ & 1 & & $<0.0001$ & 1 & & 0.0001 \\
\hline$>0.5$ & 2.2 & $(1.48 \sim 3.26)$ & & 2.29 & $(1.51 \sim 3.48)$ & \\
\hline \multicolumn{7}{|l|}{ Gender } \\
\hline Male & 2.6 & $(1.64 \sim 4.15)$ & $<0.0001$ & 2.36 & $(1.43 \sim 3.90)$ & 0.0008 \\
\hline Female & 1 & & & 1 & & \\
\hline \multicolumn{7}{|l|}{ Location } \\
\hline Left & 1 & & 0.6661 & & & \\
\hline Right & 1.09 & $(0.74 \sim 1.61)$ & & & & \\
\hline \multicolumn{7}{|l|}{ Tumour extent } \\
\hline Intrathyroidal & 1 & & 0.7443 & & & \\
\hline Extrathyroidal & 1.07 & $(0.72 \sim 1.59)$ & & & & \\
\hline \multicolumn{7}{|l|}{ BRAF mutation } \\
\hline Negative & 0.13 & $(0.02 \sim 1.12)$ & 0.0635 & & & \\
\hline Positive & 1 & & & & & \\
\hline \multicolumn{7}{|c|}{ Adenomatous hyperplasia } \\
\hline Absent & 1 & & 0.4329 & & & \\
\hline Present & 0.82 & $(0.50 \sim 1.34)$ & & & & \\
\hline \multicolumn{7}{|c|}{ Lymphocytic thyroiditis } \\
\hline Absent & 1.68 & $(1.08 \sim 2.62)$ & 0.021 & 1.41 & $(0.88 \sim 2.26)$ & 0.154 \\
\hline Present & 1 & & & 1 & & \\
\hline \multicolumn{7}{|l|}{ CD9 Expression } \\
\hline 1 & 1 & & 0.9644 & & & \\
\hline 2 & 1.23 & $(0.53 \sim 2.83)$ & & & & \\
\hline 3 & 1.00 & $(0.48 \sim 2.10)$ & & & & \\
\hline 4 & 1.01 & $(0.61 \sim 1.67)$ & & & & \\
\hline \multicolumn{7}{|l|}{ CD9 Intensity } \\
\hline 0 & 1 & & 0.0025 & 1 & & 0.0061 \\
\hline 1 & 0.62 & $(0.35 \sim 1.09)$ & & 0.51 & $(0.28 \sim 0.93)$ & \\
\hline 2 & 1.37 & $(0.81 \sim 2.34)$ & & 1.1 & $(0.63 \sim 0.1 .92)$ & \\
\hline 3 & 1.95 & $(0.90 \sim 4.24)$ & & 1.58 & $(0.69 \sim 3.58)$ & \\
\hline CD9 H-score & 1.00 & $(0.99 \sim 1.004)$ & 0.0817 & & & \\
\hline \multicolumn{7}{|c|}{ CD82 Expression } \\
\hline 1 & 1 & & 0.8485 & & & \\
\hline 2 & 1.06 & $(0.44 \sim 1.68)$ & & & & \\
\hline 3 & 1.60 & $(0.55 \sim 4.65)$ & & & & \\
\hline 4 & 1.00 & $(0.65 \sim 1.53)$ & & & & \\
\hline \multicolumn{7}{|l|}{ CD82 Intensity } \\
\hline 0 & 1 & & 0.0803 & & & \\
\hline 1 & 1.06 & $(0.67 \sim 1.68)$ & & & & \\
\hline 2 & 0.77 & $(0.44 \sim 1.35)$ & & & & \\
\hline 3 & 2.35 & $(1.06 \sim 5.21)$ & & & & \\
\hline CD82 H-score & 1.001 & $(0.99 \sim 1.003)$ & 0.6432 & & & \\
\hline
\end{tabular}

$\mathrm{OR}$ - odds ratio; $\mathrm{Cl}$ - confidence interval 


\section{Conflict of interest}

The authors declare no conflict of interest.

\section{References}

1. Hay ID, Hutchinson ME, Gonzalez-Losada T, et al. Papillary thyroid microcarcinoma: a study of 900 cases observed in a 60-year period. Surgery. 2008; 144(6): 980-987, doi: 10.1016/j.surg.2008.08.035, indexed in Pubmed: 19041007.

2. Yoon JH, Lee HS, Kim EK, et al. Short-term Follow-up US Leads to Higher False-positive Results Without Detection of Structura Recurrences in PTMC. Medicine (Baltimore). 2016; 95(1): e2435, doi: 10.1097/MD.0000000000002435, indexed in Pubmed: 26735548.

3. Siddiqui S, White MG, Antic T, et al. Clinical and Pathologic Predictors of Lymph Node Metastasis and Recurrence in Papillary Thyroid Microcarcinoma. Thyroid. 2016; 26(6): 807-815, doi: 10.1089/thy.2015.0429, indexed in Pubmed: 27117842

4. Shi C, Guo Y, Lv Y, et al. Clinicopathological Features and Prognosis of Papillary Thyroid Microcarcinoma for Surgery and Relationship with the BRAFV600E Mutational Status and Expression of Angiogenic Factors. PLoS One. 2016; 11(12): e0167414, doi: 10.1371/journal pone.0167414, indexed in Pubmed: 27936049.

5. Lim DJ, Baek KH, Lee YS, et al. Clinical, histopathological, and molecular characteristics of papillary thyroid microcarcinoma. Thyroid. 2007; 17(9): 883-888, doi: 10.1089/thy.2007.0001, indexed in Pubmed: 17956162

6. Boucheix C, Duc GH, Jasmin C, et al. Tetraspanins and malignancy. Expert Rev Mol Med. 2001; 2001: 1-17, doi: 10.1017/S1462399401002381, indexed in Pubmed: 14987371.

7. Lee J, Byun HJ, Lee MS, et al. The metastasis suppressor CD82/KAI inhibits fibronectin adhesion-induced epithelial-to-mesenchymal transition in prostate cancer cells by repressing the associated integrin signaling. Oncotarget. 2017; 8(1): 1641-1654, doi: 10.18632/oncotarget.13767, indexed in Pubmed: 27926483.

8. Zhang BH, Liu W, Li L, et al. KAI1/CD82 and MRP1/CD9 serve as mark ers of infiltration, metastasis, and prognosis in laryngeal squamous cel carcinomas. Asian Pac J Cancer Prev. 2013; 14(6): 3521-3526, indexed in Pubmed: 23886139.

9. Wu Q, Yang Y, Wu S, et al. Evaluation of the correlation of KAI1/CD82 CD44, MMP7 and $\beta$-catenin in the prediction of prognosis and metastasis in colorectal carcinoma. Diagn Pathol. 2015; 10: 176, doi: 10.1186/s13000-015-0411-0, indexed in Pubmed: 26408312.

10. Chen Z, Mustafa T, Trojanowicz B, et al. CD82, and CD63 in thyroid cancer Int J Mol Med. 2004; 14(4): 517-527, indexed in Pubmed: 15375577.

11. Kwon HJ, Min SY, Park MJ, et al. Expression of CD9 and CD82 in clear cell renal cell carcinoma and its clinical significance. Pathol Res Pract. 2014; 210(5): 285-290, doi: 10.1016/j.prp.2014.01.004, indexed in Pubmed: 24553302

12. Jazdzewski K, Boguslawska J, Jendrzejewski J, et al. Thyroid hormone receptor beta (THRB) is a major target gene for microRNAs deregulated in papillary thyroid carcinoma (PTC). J Clin Endocrinol Metab. 2011; 96(3): E546-E553, doi: 10.1210/jc.2010-1594, indexed in Pubmed: 21159845.

13. Master A, Wójcicka A, Piekiełko-Witkowska A, et al. Untranslated regions of thyroid hormone receptor beta $1 \mathrm{mRNA}$ are impaired in human clear cell renal cell carcinoma. Biochim Biophys Acta. 2010; 1802(11): 995-1005, doi: 10.1016/j.bbadis.2010.07.025, indexed in Pubmed: 20691260

14. Regina Todeschini A, Hakomori Si. Functional role of glycosphingolipids and gangliosides in control of cell adhesion, motility, and growth, through glycosynaptic microdomains. Biochim Biophys Acta. 2008; 1780(3): 421-433, doi: 10.1016/j.bbagen.2007.10.008, indexed in Pubmed: 17991443.

15. Lazo PA. Functional implications of tetraspanin proteins in cancer biology. Cancer Sci. 2007; 98(11): 1666-1677, doi: 10.1111/j.1349-7006.2007.0 0584.x, indexed in Pubmed: 17727684.

16. Kim KJ, Kwon HJ, Kim MC, et al. CD9 Expression in Colorectal Carcinomas and Its Prognostic Significance. J Pathol Transl Med. 2016; 50(6) 459-468, doi: 10.4132/jptm.2016.10.02, indexed in Pubmed: 27780340.

17. Dong T, Liu Z, Zhao S, et al. The Expression of CD9 and PIK3CD is Associated with Prognosis of Follicular Lymphoma. J Cancer. 2015; 6(12): 1222-1229, doi: 10.7150/jca.11279, indexed in Pubmed: 26535063.
18. Huang CI, Kohno N, Ogawa E, et al. Correlation of reduction in MRP-1/CD9 and KAI1/CD82 expression with recurrences in breast cance patients. Am J Pathol. 1998; 153(3): 973-983, indexed in Pubmed: 9736046.

19. Houle CD, Ding XY, Foley JF, et al. Loss of expression and altered localization of KAI1 and CD9 protein are associated with epithelial ovarian cancer progression. Gynecol Oncol. 2002; 86(1): 69-78, indexed in Pubmed: 12079303.

20. Chen Z, Gu S, Trojanowicz B, et al. Down-regulation of TM4SF is associated with the metastatic potential of gastric carcinoma TM4SF members in gastric carcinoma. World J Surg Oncol. 2011; 9: 43, doi: 10.1186/1477-7819-9-43, indexed in Pubmed: 21521534.

21. Yin M, Soikkeli J, Jahkola T, et al. Osteopontin promotes the invasive growth of melanoma cells by activating integrin $\alpha \mathrm{v} \beta 3$ and down-regulating tetraspanin CD9. Am J Pathol. 2014; 184(3): 842-858, doi: 10.1016/j. ajpath.2013.11.020, indexed in Pubmed: 24412090

22. Charrin S, le Naour F, Silvie O, et al. Lateral organization of membrane proteins: tetraspanins spin their web. Biochem J. 2009; 420(2): 133-154 doi: 10.1042/BJ20082422, indexed in Pubmed: 19426143.

23. Murayama Y, Shinomura Y, Oritani K, et al. The tetraspanin CD9 modulates epidermal growth factor receptor signaling in cancer cells. Cell Physiol. 2008; 216(1): 135-143, doi: 10.1002/jcp.21384, indexed in Pubmed: 18247373

24. Castro-Sanchez L, Soto-Guzman A, Navarro-Tito N, et al. Native type IV collagen induces cell migration through a CD9 and DDR1-dependent pathway in MDA-MB-231 breast cancer cells. Eur J Cell Biol. 2010; 89(11): 843-852, doi: 10.1016/j.ejcb.2010.07.004, indexed in Pubmed: 20709424

25. Yamaguchi H, Wyckoff J, Condeelis J. Cell migration in tumors. Cur Opin Cell Biol. 2005; 17(5): 559-564, doi: 10.1016/j.ceb.2005.08.002, indexed in Pubmed: 16098726.

26. Iwasaki T, Takeda Y, Maruyama K, et al. Deletion of tetraspanin CD9 diminishes lymphangiogenesis in vivo and in vitro. J Biol Chem. 2013; 288(4): 2118-2131, doi: 10.1074/jbc.M112.424291, indexed in Pubmed: 23223239

27. Kamisasanuki T, Tokushige $\mathrm{S}$, Terasaki $\mathrm{H}$, et al. Targeting CD9 produces stimulus-independent antiangiogenic effects predominantly in activated endothelial cells during angiogenesis: a novel antiangiogenic therapy. Biochem Biophys Res Commun. 2011; 413(1): 128-135, doi: 10.1016/j. bbrc.2011.08.068, indexed in Pubmed: 21875571.

28. Richardson MM, Jennings LK, Zhang XA. Tetraspanins and tumor progression. Clin Exp Metastasis. 2011; 28(3): 261-270, doi: 10.1007/s10585-010-9365-5, indexed in Pubmed: 21184145.

29. Huang CL, Ueno M, Liu D, et al. MRP-1/CD9 gene transduction regulates the actin cytoskeleton through the downregulation of WAVE2. Oncogene. 2006; 25(49): 6480-6488, doi: 10.1038/sj.onc.1209654, indexed in Pubmed: 16682943.

30. Takenawa T, Suetsugu S. The WASP-WAVE protein network: connecting the membrane to the cytoskeleton. Nat Rev Mol Cell Biol. 2007; 8(1): 37-48, doi: 10.1038/nrm2069, indexed in Pubmed: 17183359.

31. Tang M, Yin G, Wang F, et al. Downregulation of CD9 promotes pancreatic cancer growth and metastasis through upregulation of epiderma growth factor on the cell surface. Oncol Rep. 2015; 34(1): 350-358, doi: 10.3892/or.2015.3960, indexed in Pubmed: 25955689.

32. Hwang JR, Jo K, Lee Y, et al. Upregulation of CD9 in ovarian cancer is related to the induction of TNF- $\alpha$ gene expression and constitutive NF- $B$ activation. Carcinogenesis. 2012; 33(1): 77-83, doi: 10.1093/carcin/bgr257, indexed in Pubmed: 22095071

33. Xuan $\mathrm{H}, \mathrm{Hu} X, \mathrm{Huang} \mathrm{J}$. Role of motility-related protein-1 in promoting the development of several types of cancer (Review). Oncol Lett. 2014 7(3): 611-615, doi: 10.3892/ol.2014.1786, indexed in Pubmed: 24520284.

34. Tang Y, Bhandaru M, Cheng Y, et al. The role of the metastasis suppressor gene KAI1 in melanoma angiogenesis. Pigment Cell Melanoma Res. 2015; 28(6): 696-706, doi: 10.1111/pcmr.12399, indexed in Pubmed: 26199094

35. Ito $\mathrm{Y}$, Yoshida $\mathrm{H}$, Uruno $\mathrm{T}$, et al. KAI1 expression in thyroid neoplasms: its linkage with clinicopathologic features in papillary carcinoma. Pathol Res Pract. 2003; 199(2): 79-83, doi: 10.1078/0344-0338-00358, indexed in Pubmed: 12747469

36. Risinger JI, Custer M, Feigenbaum L, et al. Normal viability of Kai1/Cd82 deficient mice. Mol Carcinog. 2014; 53(8): 610-624, doi: 10.1002/mc.22009, indexed in Pubmed: 23401136. 